Article

\title{
Analysis of $\alpha$-and $\beta$-amanitin in Human Plasma at Subnanogram per Milliliter Levels by Reversed Phase Ultra-High Performance Liquid Chromatography Coupled to Orbitrap Mass Spectrometry
}

\author{
Thomas P. Bambauer, Lea Wagmann, Armin A. Weber and Markus R. Meyer * \\ Department of Experimental and Clinical Toxicology, Institute of Experimental and Clinical Pharmacology \\ and Toxicology, Center for Molecular Signaling (PZMS), Saarland University, 66421 Homburg, Germany; \\ thomas.bambauer@uks.eu (T.P.B.); Lea.wagmann@uks.eu (L.W.); armin.weber@uks.eu (A.A.W.) \\ * Correspondence: markus.meyer@uks.eu; Tel.: +49-6841-16-26430; Fax: +49-6841-16-26431
}

Received: 18 September 2020; Accepted: 20 October 2020; Published: 23 October 2020

\begin{abstract}
Amatoxins are known to be one of the main causes of serious to fatal mushroom intoxication. Thorough treatment, analytical confirmation, or exclusion of amatoxin intake is crucial in the case of any suspected mushroom poisoning. Urine is often the preferred matrix due to its higher concentrations compared to other body fluids. If urine is not available, analysis of human blood plasma is a valuable alternative for assessing the severity of intoxications. The aim of this study was to develop and validate a liquid chromatography (LC)-high resolution tandem mass spectrometry (HRMS/MS) method for confirmation and quantitation of $\alpha$ - and $\beta$-amanitin in human plasma at subnanogram per milliliter levels. Plasma samples of humans after suspected intake of amatoxin-containing mushrooms should be analyzed and amounts of toxins compared with already published data as well as with matched urine samples. Sample preparation consisted of protein precipitation, aqueous liquid-liquid extraction, and solid-phase extraction. Full chromatographical separation of analytes was achieved using reversed-phase chromatography. Orbitrap-based MS allowed for sufficiently sensitive identification and quantification. Validation was successfully carried out, including analytical selectivity, carry-over, matrix effects, accuracy, precision, and dilution integrity. Limits of identification were $20 \mathrm{pg} / \mathrm{mL}$ and calibration ranged from $20 \mathrm{pg} / \mathrm{mL}$ to $2000 \mathrm{pg} / \mathrm{mL}$. The method was applied to analyze nine human plasma samples that were submitted along with urine samples tested positive for amatoxins. $\alpha$-Amanitin could be identified in each plasma sample at a range from 37-2890 pg/mL, and $\beta$-amanitin was found in seven plasma samples ranging from $<20-7520 \mathrm{pg} / \mathrm{mL}$. A LC-HRMS/MS method for the quantitation of amatoxins in human blood plasma at subnanogram per milliliter levels was developed, validated, and used for the analysis of plasma samples. The method provides a valuable alternative to urine analysis, allowing thorough patient treatment but also further study the toxicokinetics of amatoxins.
\end{abstract}

Keywords: amatoxins; amanitin; mushroom poisoning; LC-HRMS/MS; bioanalysis

Key Contribution: Sufficient sensitivity of $0.02 \mathrm{ng} / \mathrm{mL}$ for $\alpha$ - and $\beta$-amanitin was provided for plasma analysis of amatoxins in a clinical setting. Amatoxins could be identified in plasma samples up to $72 \mathrm{~h}$ after a poisoning event.

\section{Introduction}

Intoxication by wild mushrooms can occur when edible species are misidentified or toxic species are ingested accidentally by children or used intentionally in the case of suicide attempts or homicides [1-3]. 
Some mushroom poisoning syndromes are potentially life-threatening [3-5]. Mushrooms that contain amatoxins especially have been known to be the main cause of severe to fatal mushroom poisoning for decades [6,7]. Recently, De Olano et al. reported a mortality rate of $8.8 \%$ of suspected amatoxin poisoning cases $(n=148)$ from 2008 to 2018 in the US, while studies from Portugal reported $11.8 \%$ (1990-2008; $n=93)$ and South China just under 20\% (1994-2012; $n=624)$ [8-10]. This diversity could be explained by different strategies in intensive care and by endemic species in Asia containing higher amounts of amatoxins [10-13]. These thermally stable cyclic octapeptides can be found in Amanita phalloides and in many other Amanita species, as well as in certain species of the genera Lepiota, Galerina, and Pholiotina [11,13-16]. Once absorbed, amatoxins are rapidly excreted into bile and urine, and there is no evidence of metabolism, such as cleavage by proteases [13]. Thus, enterohepatic circulation, according to a study with perfused rat livers, is assumed to have a big impact on the prognosis $[13,17]$. After importing into hepatocytes via the organic anion transporting protein 1B3 (OATP1B3), amatoxins bind to RNA polymerase II in the cell nuclei with high affinity (nM range), leading to apoptosis $[18,19]$. The first signs of intoxication appear as gastro-intestinal symptoms 6-24 $\mathrm{h}$ (mostly 10-12 h) after the mushroom meal, whose delay is characteristic but not specific for amatoxin poisoning [13]. Nevertheless, slightly toxic or edible but rotten mushrooms cause most mushroom poisonings, and they can manifest in very similar moderate gastro-intestinal symptoms $[1,20,21]$. The first symptoms of acute hepatic injury are typically seen on the third day after ingestion. Over the following days, the poisoning can evolve into a serious hepatorenal syndrome with the potential failure of the liver and kidney, requiring a liver transplant or human albumin dialysis [13]. The most frequently used antidotal therapy options consist of penicillin $\mathrm{G}, N$-acetylcysteine (NAC), and silibinin/silymarin. It is controversially debated, but a slight benefit for the latter in monotherapy may exist (Grade II-2 evidence) $[6,13,22,23]$. An early start of therapeutic and supportive treatment as well as the application of activated charcoal is essential to prevent the progression of the syndrome [13,22,24,25]. To allow thorough treatment, a fast exclusion or confirmation of amatoxin presence in human biosamples at an early stage of any suspected mushroom poisoning should be possible. Urine is usually the matrix of choice for such analysis due to higher concentrations compared to other body fluids [26]. Several methods were published for their analysis in urine by using LC-MS, LC-(HR)MS/MS, capillary zone electrophoresis, HPLC, radioimmunoassay, ELISA, and recently a lateral flow immunoassay [27-37]. Also, blood plasma or serum can be used as demonstrated earlier [33,34,38-41]. To our knowledge, only one study (in English) was published where the toxins were also found in human plasma or serum samples by using mass spectrometry [41]. Providing a limit of detection (LOD) of $200 \mathrm{pg} / \mathrm{mL}$, Filigenzi et al. were able to identify $\alpha$-amanitin by using mass spectrometry in two serum samples that had been taken within the first $24 \mathrm{~h}$ after ingestion, while three others, sampled after 24-48 h, were negative [41]. Usually, only trace amounts of amatoxins are circulating in blood after $24 \mathrm{~h}$ of ingestion. Thus, LODs of $<200 \mathrm{pg} / \mathrm{mL}$ are needed to analyze for amatoxins in human plasma or serum, particularly when samples were taken $>24 \mathrm{~h}$ after ingestion. Although urine is the matrix of choice, human plasma/serum is a valuable additional tool, e.g., in cases when the sampling of urine is not possible. Moreover, analyzing for low amounts of amatoxins in the plasma or serum would allow us to monitor the effectiveness of secondary detoxification measures and to elucidate still unknown details of amatoxin toxicokinetics.

Therefore, the aim of this study was to develop and validate a fast and sensitive liquid chromatography (LC)-high resolution mass spectrometry (HRMS/MS) method for confirmation and quantitation of $\alpha$ - and $\beta$-amanitin in human plasma. Plasma samples of humans after a suspected intake of amatoxin containing mushrooms are analyzed. The amounts of toxins are then compared with published data. Furthermore, results are compared with amounts of $\alpha_{-}^{-}$, and $\beta$-amanitin in matched urine samples, analyzed using a published method [42]. 


\section{Results}

\subsection{Method Development}

Sample preparation consisting of protein precipitation by acetonitrile, aqueous liquid-liquid extraction (A-LLE) by dichloromethane, and solid-phase extraction (SPE) was necessary to allow sufficient enrichment of analytes $\alpha$-amanitin, $\beta$-amanitin, and the internal standard (IS) $\gamma$-amanitin methyl ether (Figure 1) as well as removal of the biomatrix. A similar strategy was published by Filigenzi et al. [41]. Before SPE was performed, the A-LLE extract had to be acidified because $\beta$-amanitin was only retained in the SPE column when in the protonated (uncharged) form. Strata X-Drug B cartridges (mixed-mode strong cation-exchange resin) and a similar SPE protocol had been used successfully in a previous study [30]. In the current study, we determined an extraction recovery of $50.2 \%$ (coefficient of variation $(\mathrm{CV})=11.4 \%), 55.7 \%(\mathrm{CV}=8.4 \%)$, and $87.6 \%(\mathrm{CV}=19.8 \%)$ for $\alpha$-amanitin, $\beta$-amanitin, and $\gamma$-amanitin methyl ether (internal standard), respectively. Filigenzi et al. reported a significantly higher recovery of $95 \%(\mathrm{CV}=8.8 \%)$ for $\alpha$-amanitin (recovery for $\beta$-amanitin not reported) in serum samples [41].

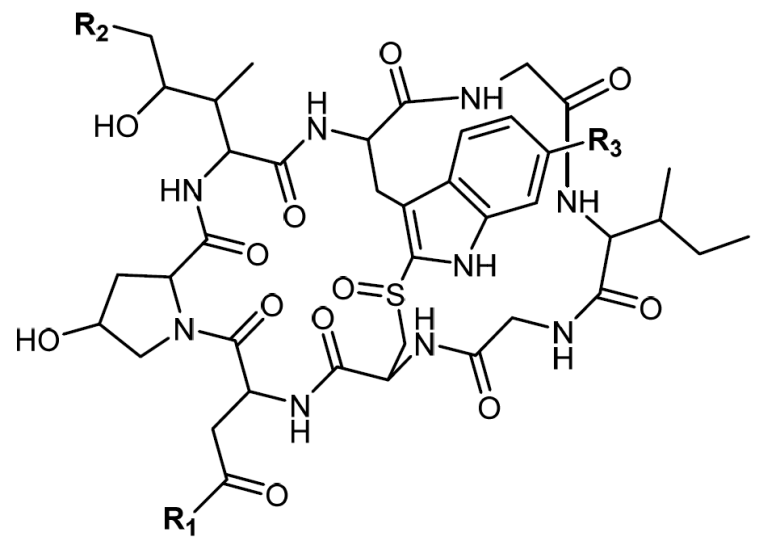

$\alpha$-Amanitin: $\mathrm{R}_{1}=\mathrm{NH}_{2}, \mathrm{R}_{2}=\mathrm{OH}, \mathrm{R}_{3}=\mathrm{OH}$
$\beta$-Amanitin: $\mathrm{R}_{1}=\mathrm{OH}, \mathrm{R}_{2}=\mathrm{OH}, \mathrm{R}_{3}=\mathrm{OH}$
$\gamma$-Amanitin methyl ether: $\mathrm{R}_{1}=\mathrm{NH}_{2}, \mathrm{R}_{2}=\mathrm{H}, \mathrm{R}_{3}=\mathrm{OCH}_{3}$

Figure 1. Structures of $\alpha$ - and $\beta$-amanitin and the internal standard of $\gamma$-amanitin methyl ether.

High-resolution signals of protonated molecules $\left(\mathrm{MH}^{+}\right)$of $\alpha$ - and $\beta$-amanitin were used for quantification, and their specific parallel reaction monitoring (PRM) MS ${ }^{2}$ fragment ion at m/z 259.1275 allowed identification. Normalized collision energy (NCE) of $28 \%$ provided the highest abundance of this fragment ion. The best sensitivity in terms of LOIs was achieved when the isolation window was widened to $\mathrm{m} / \mathrm{z} 4.5$ for inclusion of $\alpha$ - and $\beta$-amanitin and their most common ${ }^{13} \mathrm{C}$-isotopes [43]. In order to discriminate $\alpha$-from $\beta$-amanitin, baseline separation in LC was mandatory, which was achieved (Figure 2) by using an Accucore PhenylHexyl column and a gradient elution (Table 1). 


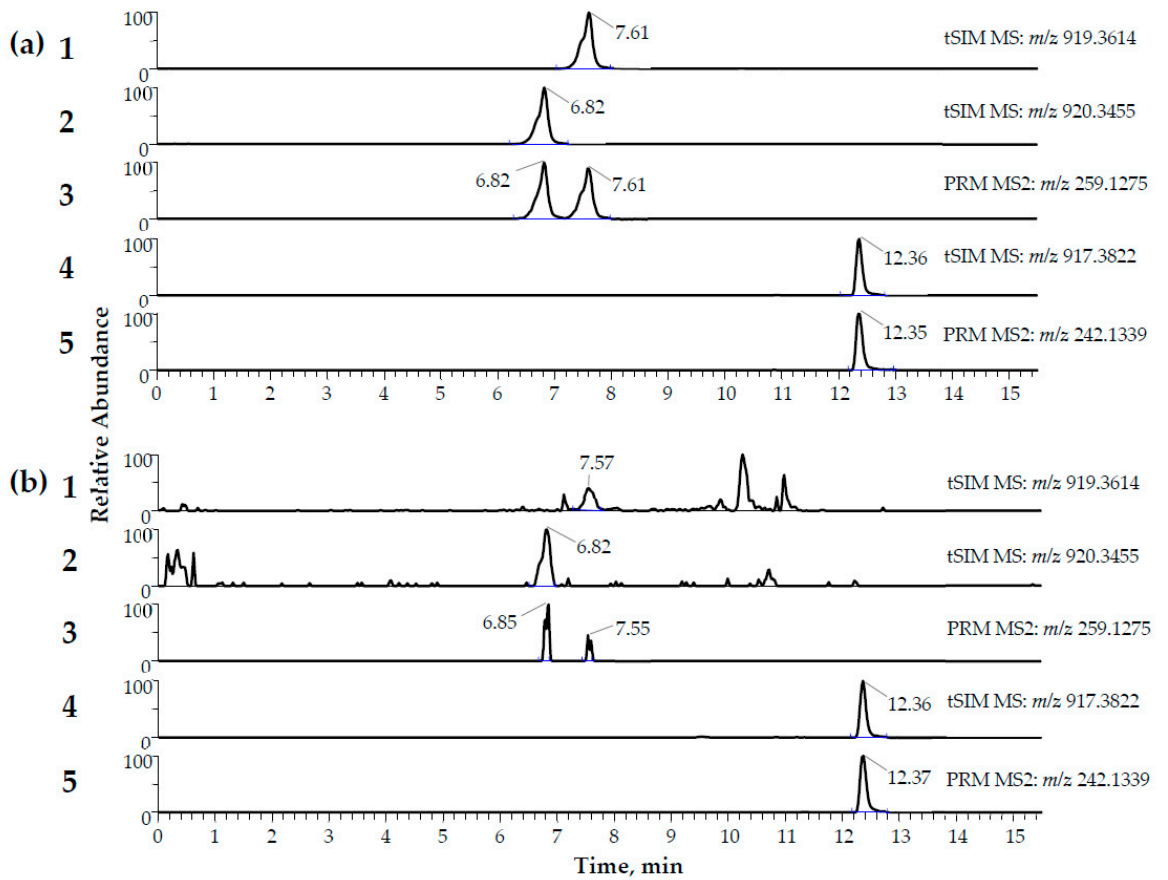

Figure 2. Extracted ion chromatograms $\left(\mathrm{MH}^{+}\right)$of matrix-matched quality control samples $((\mathbf{a})=2000 \mathrm{pg} / \mathrm{mL},(\mathbf{b})=20 \mathrm{pg} / \mathrm{mL})$ of $\alpha$-amanitin $(\mathrm{m} / \mathrm{z}=919.3614$ at $7.61 \mathrm{~min}$ in $(\mathbf{a}) \mathbf{1}$ and $7.57 \mathrm{~min}$ in (b)1), $\beta$-amanitin ( $\mathrm{m} / \mathrm{z}=920.3614$ at $6.82 \mathrm{~min}$ in (a)2 and (b)2), and the internal standard (IS) $\gamma$-amanitin methyl ether $(\mathrm{m} / \mathrm{z}=917.3822$ at $12.36 \mathrm{~min}$ in (a) 4 and (b)4). The ion chromatograms of the characteristic fragment ions for the identification of $\alpha$ - and $\beta$-amanitin in $\mathrm{MS}^{2}$ are shown in (a)3 and (b)3. The ion chromatograms of the characteristic fragment ions for the identification of the IS are shown in (a) 5 and (b)5. The mass deviation was set to $5 \mathrm{ppm}$.

Table 1. The elution profile. The steps are ramping steps for the eluent ratio $(\%)$ and flow rate $(\mathrm{mL} / \mathrm{min})$.

\begin{tabular}{cccccc}
\hline \multirow{2}{*}{ Step } & Time, $\mathbf{m i n}$ & Duration, sec & $\begin{array}{c}\text { Flow Rate, } \\
\mathbf{m L} / \mathbf{m i n}\end{array}$ & \multicolumn{2}{c}{ Eluent Ratio } \\
\cline { 5 - 6 } & & & & $\mathbf{A}^{\mathbf{a}}$ & $\mathbf{B}^{\mathbf{b}}$ \\
\hline $\mathbf{1}$ & 0.00 & 60 & 0.30 & 99.0 & 1.0 \\
$\mathbf{3}$ & 1.00 & 120 & 0.30 & 99.0 & 1.0 \\
$\mathbf{4}$ & 3.00 & 420 & 0.20 & 85.0 & 15.0 \\
$\mathbf{5}$ & 10.00 & 150 & 0.20 & 70.0 & 30.0 \\
$\mathbf{6}$ & 12.50 & 90 & 0.20 & 1.0 & 99.0 \\
$\mathbf{7}$ & 14.00 & 0 & 0.30 & 1.0 & 99.0 \\
$\mathbf{8}$ & 14.00 & 89 & 0.30 & 99.0 & 1.0 \\
$\mathbf{9}$ & 15.48 & 1 & 0.30 & 99.0 & 1.0 \\
& 15.50 & 0 & 0.05 & 99.0 & 1.0 \\
\hline
\end{tabular}

a eluent A: water, ammonium acetate $8 \mathrm{mM}$, acetic acid $0.05 \%(v / v), 5 \mathrm{ppm}$ ascorbic acid, ${ }^{\mathrm{b}}$ eluent $\mathrm{B}$ : acetonitrile $49.5 \%(v / v)$, methanol $49.5 \%(v / v)$, water $1 \%(v / v)$, ammonium acetate $4 \mathrm{mM}$, acetic acid $0.05 \%(v / v)$.

\subsection{Method Validation}

No interfering signals were observed in the selectivity and analyte carry-over experiments. Matrix effects (ME) of the lower quality control $\left(\mathrm{QC}_{\mathrm{Low}}, 60 \mathrm{pg} / \mathrm{mL}\right)$ were $106 \%(\mathrm{CV}=12.0 \%), 109 \%$ $(\mathrm{CV}=16.6 \%)$, and $102 \%(\mathrm{CV}=9.0 \%)$ for $\alpha$-amanitin, $\beta$-amanitin, and the IS, respectively. MEs at $\mathrm{QC}_{\text {High }}$ samples $(1600 \mathrm{pg} / \mathrm{mL})$ were $102 \%(\mathrm{CV}=3.4 \%), 104 \%(\mathrm{CV}=3.7 \%)$, and $91.0 \%(\mathrm{CV}=13.7 \%)$ for $\alpha$-amanitin, $\beta$-amanitin, and the IS, respectively.

Amatoxins at concentrations of $20 \mathrm{pg} / \mathrm{mL}$ could be reliably identified across all runs and at several days (Figure 2). A linear regression, weighted by $1 / \mathrm{x}^{2}$, was used for quantification of $\alpha$ - and 
$\beta$-amanitin. In 6 calibrations on different days, mean $R^{2}$ was $0.9973(S D=0.0013)$. Every single $R^{2}$ for each calibration was $>0.9950$. The results of all accuracy, precision, and dilution integrity experiments are summarized in Tables 2 and 3. In brief, all results matched the acceptance criteria. The dilution integrity allowed us to determine concentrations above the calibration range up to $100,000 \mathrm{pg} / \mathrm{mL}$. The accuracy and precision of a 1:2 dilution were tested for cases when less sample material might be available for analysis. It should be mentioned that limits of identification (LOI) and lower limits of quantification (LLOQ) are increased by factor 2 in these cases.

Table 2. Intra-day accuracy, precision, and dilution integrity 1:2 and 1:50 of $\alpha$ - and $\beta$-amanitin $(\alpha, \beta)$. Calculated values are given with their standard deviations.

\begin{tabular}{|c|c|c|c|c|c|c|c|c|}
\hline \multirow[t]{2}{*}{ Intra-Day $(n=5)$} & \multicolumn{2}{|c|}{$\begin{array}{c}\text { Nominal Conc., } \\
\mathrm{pg} / \mathrm{mL}\end{array}$} & \multicolumn{2}{|c|}{ Calculated Conc., pg/mL } & \multicolumn{2}{|c|}{ Accuracy, \% } & \multicolumn{2}{|c|}{ Precision, $\%$} \\
\hline & $\alpha$ & $\beta$ & $\alpha$ & $\beta$ & $\alpha$ & $\beta$ & $\alpha$ & $\beta$ \\
\hline QC1 (LLOQ) & 20 & 20 & $19.5 \pm 2.17$ & $19.1 \pm 2.22$ & -2.7 & -4.5 & 11 & 12 \\
\hline QC2 (low) & 60 & 60 & $62.0 \pm 5,76$ & $53.0 \pm 3.89$ & 3.4 & -12 & 9.3 & 7.3 \\
\hline QC3 (mid) & 400 & 400 & $421 \pm 28.4$ & $411 \pm 27.4$ & 5.3 & 2.8 & 6.7 & 6.7 \\
\hline QC4 (high) & 1600 & 1600 & $1510 \pm 23.4$ & $1570 \pm 15.5$ & -5.4 & -1.6 & 1.6 & 1.0 \\
\hline QC Dil F2 $^{a}$ & $1000 * 2$ & $1000 * 2$ & $2140 \pm 81.3$ & $2065 \pm 103$ & 6.8 & 3.2 & 3.8 & 5.0 \\
\hline QC Dil F50 b & $40 * 50$ & $40 * 50$ & $1940 \pm 130$ & $1757 \pm 157$ & -3.1 & -12 & 6.7 & 8.9 \\
\hline
\end{tabular}

a diluted QC sample of $2000 \mathrm{pg} / \mathrm{mL} \alpha$ - and $\beta$-amanitin, dilution factor: $2{ }^{\mathrm{b}}$ diluted QC sample of $2000 \mathrm{pg} / \mathrm{mL} \alpha$ - and $\beta$-amanitin, dilution factor: 50 .

Table 3. Inter-day accuracy and precision of $\alpha$ - and $\beta$-amanitin $(\alpha, \beta)$. The calculated values are given with their standard deviations.

\begin{tabular}{lcccccccc}
\hline \multirow{2}{*}{$\begin{array}{l}\text { Intra-Day }(n=5), \\
\text { 3 runs }\end{array}$} & \multicolumn{2}{c}{$\begin{array}{c}\text { Nominal conc., } \\
\text { pg/mL }\end{array}$} & \multicolumn{2}{c}{ Calculated conc., pg/mL } & Accuracy, \% & Precision, \% \\
\cline { 2 - 10 } & $\alpha$ & $\beta$ & $\alpha$ & $\beta$ & $\alpha$ & $\beta$ & $\alpha$ & $\beta$ \\
\hline QC1 (LLOQ) & 20 & 20 & $21.0 \pm 2.10$ & $19.9 \pm 2.72$ & 4.9 & -0.4 & 10 & 14 \\
\hline QC2 (low) & 60 & 60 & $64.2 \pm 4.92$ & $55.8 \pm 5.60$ & 6.9 & -7.0 & 7.7 & 10 \\
\hline QC3 (mid) & 400 & 400 & $409 \pm 24.2$ & $401 \pm 25.0$ & 2.2 & 0.3 & 5.9 & 6.2 \\
\hline QC4 (high) & 1600 & 1600 & $1514 \pm 111$ & $1535 \pm 107$ & -5.4 & -4.1 & 7.4 & 7.1 \\
\hline
\end{tabular}

\subsection{Applicability}

The results of the analyzed plasma samples and matched urine samples are listed in Table 4 . In summary, $\alpha$-amanitin could be identified in all nine plasma samples, $\beta$-amanitin only in seven. According to the reports by Tang et al. and Sgambelluri et al., in a few species of the genera Amanita and Lepiota, $\alpha$-amanitin but no $\beta$-amanitin might be found [11,44]. Regarding both negative results in plasma, it is unlikely that $\beta$-amanitin was completely absent, as it may be present in concentrations below the LOI, since it was identified in the corresponding urine samples. Concentration of $\alpha$-amanitin in plasma varied from 37 to $2890 \mathrm{pg} / \mathrm{mL}$ and $\beta$-amanitin from $<20$ to $7520 \mathrm{pg} / \mathrm{mL}$. 
Table 4. Analysis results of blood plasma and urine samples of suspected mushroom poisoning cases.

\begin{tabular}{|c|c|c|c|c|c|c|c|c|c|c|}
\hline \multicolumn{2}{|l|}{ Case } & 1 & 2 & 3 & 4 & 5 & 6 & 7 & 8 & 9 \\
\hline \multicolumn{2}{|c|}{ Amounts of mushrooms ingested } & $3-4$ & $2-3$ & $2-3$ & unk. & 3 & 1 cap & unk. & unk. & unk. \\
\hline \multicolumn{2}{|c|}{ Sampling time after intake ${ }^{a}, h$} & 13 & 13 & 13 & 40 & 48 & 15 & $48-72$ & 72 & 72 \\
\hline \multirow{2}{*}{$\begin{array}{l}\text { Blood plasma } \\
\text { concentration, pg/mL }\end{array}$} & $\alpha$-Amanitin & 277 & 259 & 137 & 37 & $194^{\mathrm{b}}$ & 245 & $<40^{b}$ & 63 & 2890 \\
\hline & $\beta$-Amanitin & 1200 & 1050 & 578 & $<20$ & n.i. ${ }^{b}$ & 176 & n.i. ${ }^{b}$ & 41 & 7520 \\
\hline \multirow{2}{*}{$\begin{array}{l}\text { Urinary concentration, } \\
\mathrm{ng} / \mathrm{mL}\end{array}$} & $\alpha$-Amanitin & 12 & 36 & 8.1 & n.i. & $<1$ & 19 & 4.6 & 2.5 & 24 \\
\hline & $\beta$-Amanitin & 55 & 149 & 28 & n.i. & $<1$ & 32 & 2.0 & 23 & 164 \\
\hline \multicolumn{2}{|c|}{ Urinary creatinine, $\mathrm{mg} / \mathrm{dL}$} & 86 & 140 & 42 & 169 & 232 & 112 & 220 & 268 & 60 \\
\hline
\end{tabular}

${ }^{a}$ time of ingestion is based on anamnestic data, ${ }^{b}$ reduced amount of blood plasma $(1.25 \mathrm{~mL})$ utilized for quantification. Abbreviations: unk. = unknown; n.i. = not identified

\section{Discussion}

Exclusion or confirmation of an intake of amanitin containing mushrooms using $\alpha$-and $\beta$-amanitin as biomarkers is often requested to avoid expensive and time-consuming treatment of every suspected case. The sufficient sensitivity of such an analysis is crucial as hospitalization is often late after intake and only trace amounts of toxins can be found [26,27]. Therefore, urine is considered as the biomatrix of choice, as concentrations of amatoxins are usually higher here than in serum or plasma $[26,45]$. The major drawbacks of urine are a reduced output in the case of decreased renal function and acute renal failure, occurring in some amatoxin but also other mushroom poisoning cases, and a higher intra- and interindividual variability in the complexity of urine as biomatrix. If therapy measures like fluid replacement or forced diuresis have been conducted, low amounts of amatoxins in urine could have been further diluted. Some authors also reported high matrix effects, particularly when using positive electrospray ionization [35,42]. Therefore, a method for the determination of amatoxins in blood plasma may overcome some of these limitations. However, such a method requires sufficient sensitivity. According to Busi et al., concentrations in plasma should be about 10 times lower than in urine (without considering urinary creatinine for normalization) [34,46]. A reliable and sufficiently powerful method for amatoxin analysis in plasma would therefore be an important tool not only for acute clinical purposes but also in forensic toxicology and further research on toxicokinetics of amatoxins. To the best of our knowledge, there is currently no published method, which might support existing methods for urine analysis in terms of relative sensitivity and, thus, usefulness in an analytical setting.

\subsection{Method Development}

$\gamma$-Amanitin methyl ether was used as an internal standard (IS) because of the similar structure (Figure 1), extraction, and elution behavior (Figure 2) [35,42]. Luo et al. published the production of ${ }^{15} \mathrm{~N}_{10}$ - $\alpha$-amanitin that already has been successfully used by Abbott et al. as an IS for their LC-MS/MS method [29,47]. Unfortunately, this or other structure-analog compounds of $\alpha$ - or $\beta$-amanitin that can be used as internal standards are currently not commercially available.

\subsection{Method Validation}

In summary, the matrix effects were very low compared to reported MEs in urine samples [29,42,48]. The method by Abbott et al. especially suffered from high matrix effects for $\alpha-(25.5 \% \pm 2.50 \%)$ and $\beta$-amanitin (38.1\% $\pm 1.29 \%)$, determined in pooled urine samples [29].

According to the ICH M10 guideline draft, several stability studies should be examined [49]. Li et al. provided the following stability data of $\alpha$-amanitin in plasma: short-term, long-term, freeze-thaw ( 3 cycles), and postpreparative storage stability ( $n=6 ; 3$ concentration levels evaluated for each experiment) [50]. In addition, Zhang et al. also included $\beta$-amanitin in their stability studies in plasma, serum, and urine ( $n=3$; after 1, 2, 4, and 8 weeks) [33]. Maurer et al. provided most of the required stability data for the toxins and the IS $\gamma$-amanitin methyl ether as well as long-term stability in stock 
solutions for 6 months [35]. In none of these studies could any instability or decomposition exceeding $10 \%$ loss of recovery of $\alpha-, \beta$-amanitin, or the IS be detected.

\subsection{Applicability}

Plasma concentrations shown in Table 4 were in line with the findings of Filigenzi et al. that were already mentioned, but differed from the results of the most comprehensive study of amatoxins in humans by Jaeger et al., who reported values in plasma ranging from 8000 to 190,000 pg/mL and from 23,500 to $162,000 \mathrm{pg} / \mathrm{mL}$ for $\alpha$-and $\beta$-amanitin, respectively [26,41]. However, Jaeger et al. could detect amatoxins only in 11 of a total of 43 human plasma samples, of which 40 were taken between 18 and $96 \mathrm{~h}$ after the ingestion of mushrooms. They used a not validated (e.g., no data on selectivity) HPLC-UV method, based on a publication by Jehl et al. in 1985 with LODs for each toxin of $5000 \mathrm{pg} / \mathrm{mL}[26,51]$.

Figure 3 illustrates the correlation of plasma concentrations with uncorrected (Figure 3a) and creatinine-normalized urinary concentrations (Figure 3b). Creatinine-normalized urinary concentrations showed a better linear correlation and may thus be more comparable with plasma concentrations and therefore more suitable for interpretation than uncorrected ones. Furthermore, the effects of urine dilution, e.g., caused by therapy measures such as forced diuresis, can be normalized. This in turn allows us to compare results with creatinine normalized values of other studies. Thus, concentrations of amatoxins in urine should be published together with urinary creatinine. The time window of sampling after ingestion of the mushroom meal varied from 13 to $72 \mathrm{~h}$. It must be kept in mind that this information, as well as the suspected amounts of ingested mushrooms, is based on patient information, and should be taken with care. A rapid decrease of toxin concentrations in both matrices can be observed when comparing values from samples collected after 13-15 h to samples collected after more than $40 \mathrm{~h}$ (Figure 4). It would be interesting to have data from more samples, particularly sampled before $13 \mathrm{~h}$ and between 15 and $40 \mathrm{~h}$ in order to make further conclusions. The determined concentrations of amatoxins in samples of case 9 seemed to be comparatively high, especially, when the late sampling time of approximately $72 \mathrm{~h}$ is considered. This patient suffered already from multi-organ failure when the samples were taken and shortly died afterward before liver transplantation could be realized. Such uncommon early deaths in the course of amatoxin poisoning were also described by Zilker and Faulstich [13]. For therapeutic reasons, it would be interesting to know, whether late-arising or persisting high concentrations of amatoxins in the blood may indicate a multi-organ failure.

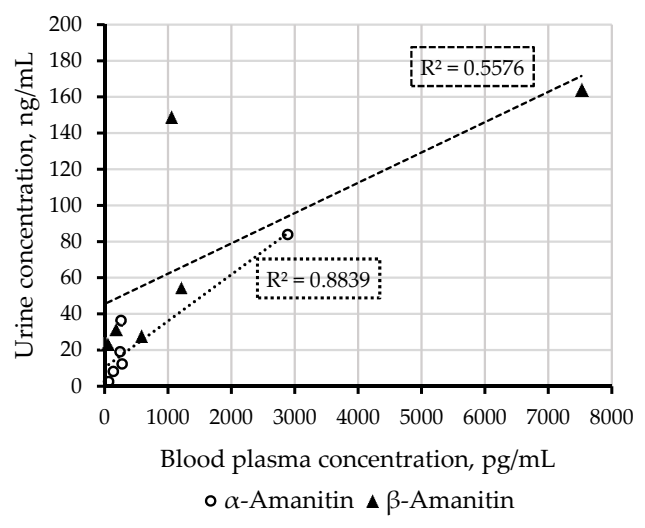

(a)

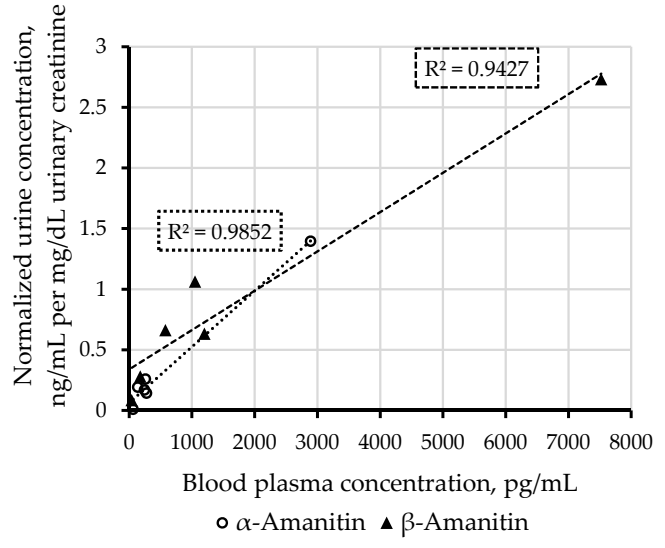

(b)

Figure 3. (a) Urinary concentrations $(\mathrm{ng} / \mathrm{mL})$ of $\alpha$-and $\beta$-amanitin in patient case samples plotted against concentrations $(\mathrm{pg} / \mathrm{mL})$ in matched blood plasma samples; (b) creatinine-normalized urinary concentrations $((\mathrm{ng} / \mathrm{mL}) /(\mathrm{mg} / \mathrm{dL}))$ of $\alpha$-and $\beta$-amanitin in patient case samples plotted against concentrations $(\mathrm{pg} / \mathrm{mL})$ in matched blood plasma. 


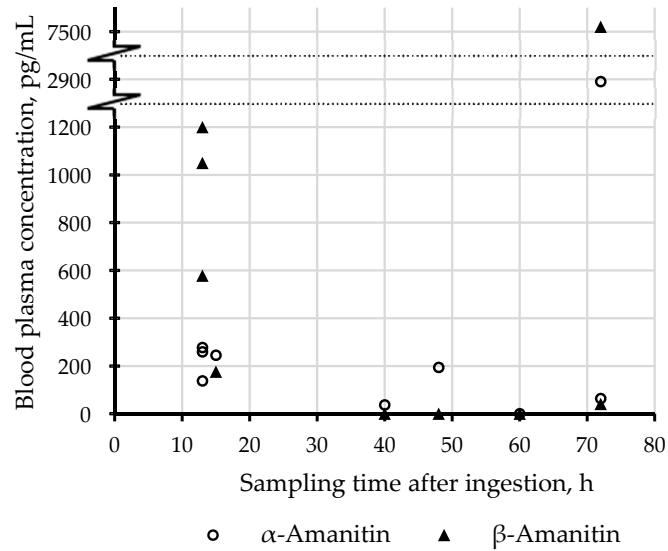

(a)

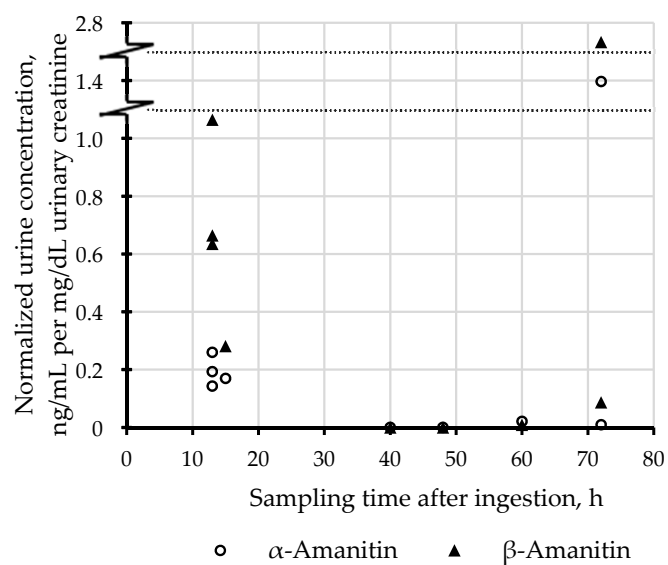

(b)

Figure 4. (a) Plasma concentrations (pg/mL) of $\alpha$-and $\beta$-amanitin in patient case samples plotted against sampling time after the ingestion of toxic mushrooms; (b) creatinine-normalized urinary concentrations $((\mathrm{ng} / \mathrm{mL}) /(\mathrm{mg} / \mathrm{dL}))$ of $\alpha$-and $\beta$-amanitin in patient case samples plotted against sampling time after the ingestion of toxic mushrooms.

\section{Conclusions}

A sufficiently sensitive and rather fast analytical method for the determination of $\alpha$-and $\beta$-amanitin down to $20 \mathrm{pg} / \mathrm{mL}$ in blood plasma was developed, validated, and applied to analyze patient samples. Analysis showed that such sensitivity is needed for the reliable identification of these biomarkers. The presented method is an alternative in cases when urine as a biomatrix is not available. Furthermore, this method may allow us to answer still unsolved questions in toxicokinetics of amatoxins and could be applied to monitor plasma concentrations during therapy in order to evaluate the effectivity of secondary detoxification measures.

\section{Materials and Methods}

\subsection{Chemicals and Reagents}

$\alpha$ - and $\beta$-amanitin with purity of $\geq 90 \%$ and $\sim 90 \%$, respectively, were purchased from Sigma-Aldrich (Taufkirchen, Germany) and $\gamma$-amanitin methyl ether was donated by Prof. Dr. Heinz Faulstich (Max-Planck-Institute for Cell Biology, Ladenburg, Germany). Methanol (MeOH), acetonitrile $(\mathrm{ACN})$, dichloromethane (DCM), formic acid, and other chemicals were of analytical grade or better and were purchased from VWR (Darmstadt, Germany). All chemicals used for the preparation of eluents for LC-MS were of LC-MS grade except for acetic acid and ascorbic acid. Water was purified using a Milli-Q water purification system (Merck KGaA, Darmstadt, Germany) to reach a resistivity of $18.2 \mathrm{M} \Omega \cdot \mathrm{cm}$.

\subsection{Stock Solutions for Calibration and Control Samples}

Two lots of stock solutions were prepared by dissolving $\alpha$ - and $\beta$-amanitin at a concentration of $1000 \mu \mathrm{g} / \mathrm{mL}$ in $\mathrm{MeOH}$ for the preparation of stock solutions for calibration and control samples, respectively. Six levels of methanolic calibration stock solutions were prepared via dilution series with concentrations of $\alpha$ - and $\beta$-amanitin as follows: 50,000, 37,500, 25,000, 12,500, 2500, and $500 \mathrm{pg} / \mathrm{mL}$. Five levels of methanolic stock solutions for QC samples were prepared: 50,000, 40,000, 10,000, 1500, and $500 \mathrm{pg} / \mathrm{mL}$. A solution of $\gamma$-amanitin methyl ether at $2.5 \mu \mathrm{g} / \mathrm{mL}$ was prepared using a 1:1 mixture of purified water and $\mathrm{MeOH}$. This solution was further diluted to $12,500 \mathrm{pg} / \mathrm{mL}$ in $\mathrm{MeOH}$. In the following, $100 \mu \mathrm{L}$ of this solution was added to each sample as an IS. All of the above-mentioned solutions were stored at $+4{ }^{\circ} \mathrm{C}$. 


\subsection{LC-HRMS/MS Apparatus}

A Thermo Fisher Scientific Dionex UltiMate 3000 RS UHPLC system (Dreieich, Germany) was used with a quaternary UltiMate 3000 RS pump and an UltiMate WPS-3000 RS autosampler. The system and all its components were controlled by Thermo Fisher Chromeleon software version 6.80 SR11 (Thermo Fisher Scientific, San Jose, CA, USA). The LC system was coupled to a Thermo Fisher Q-Exactive Plus, equipped with a heated electrospray ionization II source (HESI-II). The conditions of HESI-II were adopted from Helfer et al. [52]: sheath gas, 60 arbitrary units (AU); auxiliary gas, $10 \mathrm{AU}$; spray voltage, $4.00 \mathrm{kV}$; heater temperature, $320^{\circ} \mathrm{C}$; ion transfer capillary temperature, $320{ }^{\circ} \mathrm{C}$; and S-lens radio frequency (RF) level, $60.0 \%$. External mass calibration was conducted as recommended by the manufacturer. Targeted selected ion monitoring (t-SIM) experiments were performed using the following scan parameters: General: runtime, 0 to $15.5 \mathrm{~min}$, polarity, positive; in-source collision-induced dissociation (CID), $0.0 \mathrm{eV}$; inclusion, on; SIM: microscans, 1; resolution, 70,000; automatic gain control (AGC) target, 5e4; maximum injection time (IT), 200 ms; multiplex (MSX) count, 1 ; isolation window, $4.5 \mathrm{~m} / \mathrm{z}$; isolation offset, $0.0 \mathrm{~m} / \mathrm{z}$; spectrum data type, profile. Simultaneously, PRM experiments were performed for unambiguous identification of the analytes via specific mass fragments in $\mathrm{MS}^{2}$ scans. The PRM settings were as follows: General: runtime, 0 to $15.5 \mathrm{~min}$, polarity, positive; in-source CID, $0.0 \mathrm{eV}$; dynamic retention time (RT), off; default charge state, 1 ; inclusion, on; MS $^{2}$ : microscans, 1; resolution, 70,000; AGC target, 2e5; maximum IT, $100 \mathrm{~ms}$; loop count, 1; MSX count, 1; MSX isochroneous, on; isolation window, $4.5 \mathrm{~m} / \mathrm{z}$; isolation offset, $0.0 \mathrm{~m} / \mathrm{z}$; first fixed mass $80.0 \mathrm{~m} / \mathrm{z}$; NCE in high collision dissociation (HCD) cell, $28 \%$; spectrum data type, profile. An inclusion list containing the exact masses of protonated, positively charged analytes $\left(\mathrm{MH}^{+}\right)$was used: $\alpha$-amanitin ( $m / z$ 919.3614), $\beta$-amanitin ( $m / z$ 920.3455), $\gamma$-amanitin $(m / z$ 903.3665), and $\gamma$-amanitin methyl ether $(\mathrm{m} / \mathrm{z}$ 917.3822). The customized tolerance of mass deviations for this inclusion list was set to $10 \mathrm{ppm}$.

\subsection{Chromatography Setup}

Gradient elution was performed on a Thermo Fisher Accucore PhenylHexyl column $(150 \mathrm{~mm} \times 2.1 \mathrm{~mm}$ I.D., $2.6 \mu \mathrm{m}$ particle size) (Thermo Fisher Scientific, San Jose, CA, USA), a reversed-phase core-shell particle-based column, constantly heated at $40{ }^{\circ} \mathrm{C}$. Eluent A was purified water, buffered with $8 \mathrm{mM}$ ammonium acetate, acidified with $0.05 \%(v / v)$ acetic acid, and stabilized with 5 ppm ascorbic acid. Eluent $\mathrm{B}$ consisted of $\mathrm{ACN}$ and $\mathrm{MeOH}$ in equal shares, with $1 \%(v / v)$ purified water, $4 \mathrm{mM}$ ammonium acetate, and $0.05 \%(v / v)$ acetic acid. The elution profile is shown in detail in Table 1 . The total chromatography run time was $15.5 \mathrm{~min}$.

\subsection{Analysis Raw Data Handling and Processing}

Thermo Fisher Xcalibur software version 2.2 (Thermo Fisher Scientific, San Jose, CA, USA) was used for data handling and processing. The mass tolerance for peak integration was set to $5 \mathrm{ppm}$. ICIS peak integration settings were: smoothing points, 13; baseline window, 100; area noise factor, 2; and peak noise factor, 5 .

\subsection{Sample Preparation}

The concept of sample preparation, consisting of protein precipitation, A-LLE, and SPE, was inspired by Filigenzi et al. [41]. Briefly, a volume of $2500 \mu \mathrm{L}$ blood plasma was fortified with $100 \mu \mathrm{L}$ of the IS solution. Defined levels of matrix-matched calibration and control samples were prepared by adding $100 \mu \mathrm{L}$ of IS and stock solution to $2400 \mu \mathrm{L}$ of human blank blood plasma.

\subsubsection{A-LLE}

A volume of $6500 \mu \mathrm{L}$ ACN was added for the precipitation of proteins. The mixture was then shaken for $2 \mathrm{~min}$ and centrifuged for 2 min using 3000 rotations per minute $(1026 \times g)$, before the supernatant was decanted into another flask. After the addition of $11,000 \mu \mathrm{L}$ DCM to this supernatant, 
shaking and centrifugation were repeated. A volume of $2500 \mu \mathrm{L}$ of $0.1 \%$ formic acid was carefully added and the aqueous supernatant was transferred into a glass vial.

\subsubsection{SPE}

SPE was performed using Stata X-Drug B $33 \mu \mathrm{m}$ Polymeric Strong Cation cartridges (Phenomenex, Aschaffenburg, Germany), containing $60 \mathrm{mg}$ of sorbent mass and $3 \mathrm{~mL}$ capacity. The SPE column was preconditioned and equilibrated with $2 \times 1000 \mu \mathrm{L}$ of $\mathrm{MeOH}$ and $1000 \mu \mathrm{L}$ of $0.1 \%$ formic acid, respectively. The A-LLE extract was further diluted with $5 \mathrm{~mL}$ of $0.1 \%$ formic acid and $1000 \mu \mathrm{L}$ of $1 \%$ formic acid before it was loaded onto the column. Then, the columns were washed in two steps, using $1000 \mu \mathrm{L}$ of $1 \%$ formic acid and $2 \times 1000 \mu \mathrm{L}$ of $0.1 \%$ formic acid, respectively. The elution of analytes was induced by using $2 \times 600 \mu \mathrm{L}$ of $\mathrm{MeOH}$. The obtained eluate was gently evaporated at $75^{\circ} \mathrm{C}$ under a stream of nitrogen and subsequently reconstituted by only $20 \mu \mathrm{L}$ of $\mathrm{MeOH}$. Finally, a sample extract volume of $5 \mu \mathrm{L}$ was injected into the LC system.

\subsection{Method Validation}

Validation was planned and conducted according to the draft version of ICH Guideline on bioanalytical method validation (EMA/CHMP/ICH/172948/2019) [49]. Validation experiments included selectivity, LOIs, analyte carry-over, MEs, calibration curve, and range, including lower and upper limits of quantification (LLOQ, ULOQ), accuracy and precision (inter- and intra-day), as well as dilution integrity. The same pool of blank matrix samples was used across all validation experiments except for selectivity and ME experiments.

Selectivity was tested by analyzing a batch of 10 blood plasma samples from different donors in order to screen for potentially interfering signals from endogenous compounds.

Carry-over was checked by running zero samples (matrix blank samples spiked with IS) after a spiked sample containing analyte concentrations at the ULOQ. The final concentrations of $\alpha$ - and $\beta$-amanitin in the injected extract were $250,000 \mathrm{pg} / \mathrm{mL}$.

MEs were determined at low and high concentrated control samples $\left(\mathrm{QC}_{\mathrm{low}}=60 \mathrm{pg} / \mathrm{mL}\right.$, $\mathrm{QC}_{\text {high }}=1600 \mathrm{pg} / \mathrm{mL}$ ). Experiments were performed using six lots of pooled blank plasma samples ( 5 or 6 sources of plasma each lot), processed in triplicate. MEs were calculated for each analyte and the IS by dividing peak areas of the analytes spiked into plasma samples by those in neat standards. In addition, analyte and IS recovery at $\mathrm{QC}_{\text {high-level }}(1600 \mathrm{pg} / \mathrm{mL})$ was determined by dividing peak areas of the analytes spiked into plasma samples before extraction by those of the extracts of blank samples spiked afterward. Calculations were performed using Microsoft Excel 2016. MEs leading to deviations of $<15 \%$ and CVs of $<15 \%$ were regarded as acceptable [49].

LOIs were determined by analyzing spiked samples in triplicate. LOIs were set at the lowest concentration where the analytes could be identified in each of the samples and in a repeated analysis on another day. The definition of identification was based on Helfer et al. [52,53]. At the retention time of the analyte, the accurate mass of the precursor ion must be detected and a specific fragment of the corresponding high-resolution MS/MS spectrum must be present. The MS/MS fragment at $\mathrm{m} / \mathrm{z}$ 259.1275 was considered as specific for the identification of $\alpha$ - or $\beta$-amanitin.

Final concentrations of calibrators were at 20,100,500,1000,1.500, and $2000 \mathrm{pg} / \mathrm{mL}$ and 6 full sets of calibration samples, prepared as described in Sections 5.2 and 5.6, were analyzed on six different days. Calibration curves were calculated by using regression and weighting models, implemented in Xcalibur software version 2.2, on the ratios of full scan MS peak areas of the analytes and the IS.

The accuracy and precision were evaluated by analyzing four levels of QC samples at 20, 60, 400, and $1600 \mathrm{pg} / \mathrm{mL}$, all prepared as described in Sections 5.2 and 5.6. For the calculation of concentrations and errors, each run of the QC samples contained a full calibration. For intra-day accuracy and precision, 5 repetitions of $Q C$ samples were analyzed that ran within a day. Inter-day accuracy and precision were evaluated by including repetitions of the mentioned intra-day experiments on two 
other days. Both errors of accuracy and precision should not exceed $15 \%$, except for LLOQ samples (20\%) [49].

Dilution integrity was tested for a 1:50 dilution of the highest calibrator $(2000 \mathrm{pg} / \mathrm{mL})$. Additionally, a 1:2 dilution was tested using the same calibrator. Intra-day accuracy and precision were evaluated for these diluted samples as described above. Errors of accuracy and precision should not exceed $15 \%$, as for other QC samples [49].

\subsection{Applicability}

The applicability was tested by analyzing nine plasma samples after suspected intake of amanitin containing mushrooms. Amatoxin poisoning had already been confirmed by previous analyses of the corresponding urine samples [35,42]. Samples had been sent to the authors' laboratory for toxicological analysis and were kept frozen at $-20{ }^{\circ} \mathrm{C}$. The urine samples were again analyzed [42]. Creatinine was determined using the P.I.A. ${ }^{2}$ device from Protzek (Lörrach, Germany).

Author Contributions: Conceptualization, T.P.B. and M.R.M.; Data curation, T.P.B.; Formal analysis, T.P.B.; Investigation, T.P.B., L.W. and A.A.W.; Methodology, T.P.B. and M.R.M.; Resources, M.R.M.; Supervision, M.R.M.; Validation, T.P.B.; Visualization, T.P.B. and L.W.; Writing-original draft, T.P.B.; Writing-review \& editing, L.W., A.A.W. and M.R.M. All authors have read and agreed to the published version of the manuscript.

Funding: This research received no external funding.

Acknowledgments: We acknowledge support by the Deutsche Forschungsgemeinschaft (DFG, German Research Foundation) and Saarland University within the funding programme Open Access Publishing. We would like to thank Sascha K. Manier, Carsten Schröder, Gabriele Ulrich, Cathy M. Jacobs, Tanja M. Gampfer, Matthias J. Richter, and Selina Hemmer for their support and/or helpful discussions.

Conflicts of Interest: The authors have no competing interest to declare.

\section{References}

1. Persson, H. Mushrooms. Medicine 2016, 44, 116-119. [CrossRef]

2. Gonmori, K.; Fujita, H.; Yokoyama, K.; Watanabe, K.; Suzuki, O. Mushroom toxins: A forensic toxicological review. Forensic Toxicol. 2011, 29, 85-94. [CrossRef]

3. Brandenburg, W.E.; Ward, K.J. Mushroom poisoning epidemiology in the United States. Mycologia 2018, 110, 637-641. [CrossRef] [PubMed]

4. Govorushko, S.; Rezaee, R.; Dumanov, J.; Tsatsakis, A. Poisoning associated with the use of mushrooms: A review of the global pattern and main characteristics. Food Chem. Toxicol. 2019, 128, 267-279. [CrossRef] [PubMed]

5. White, J.; Weinstein, S.A.; De Haro, L.; Bedry, R.; Schaper, A.; Rumack, B.H.; Zilker, T. Mushroom poisoning: A proposed new clinical classification. Toxicon 2019, 157, 53-65. [CrossRef] [PubMed]

6. Poucheret, P.; Fons, F.; Dore, J.C.; Michelot, D.; Rapior, S. Amatoxin poisoning treatment decision-making: Pharmaco-therapeutic clinical strategy assessment using multidimensional multivariate statistic analysis. Toxicon 2010, 55, 1338-1345. [CrossRef]

7. Liu, J.; Chen, Y.; Gao, Y.; Walline, J.H.; Lu, X.; Yu, S.; Zhao, L.; Ge, Z.; Li, Y. N-acetylcysteine as a treatment for amatoxin poisoning: A systematic review. Clin. Toxicol. 2020, 58, 1-8. [CrossRef]

8. De Olano, J.; Wang, J.J.; Villeneuve, E.; Gosselin, S.; Biary, R.; Su, M.K.; Hoffman, R.S. Current fatality rate of suspected cyclopeptide mushroom poisoning in the United States. Clin. Toxicol. 2020, 1-4. [CrossRef]

9. Diaz, J.H. Amatoxin-containing mushroom poisonings: Species, toxidromes, treatments, and outcomes. Wilderness Environ. Med. 2018, 29, 111-118. [CrossRef]

10. Chen, Z.; Zhang, P.; Zhang, Z. Investigation and analysis of 102 mushroom poisoning cases in Southern China from 1994 to 2012. Fungal Divers. 2013, 64, 123-131. [CrossRef]

11. Tang, S.; Zhou, Q.; He, Z.; Luo, T.; Zhang, P.; Cai, Q.; Yang, Z.; Chen, J.; Chen, Z. Cyclopeptide toxins of lethal amanitas: Compositions, distribution and phylogenetic implication. Toxicon 2016, 120, 78-88. [CrossRef] [PubMed]

12. Cai, Q.; Cui, Y.Y.; Yang, Z.L. Lethal Amanita species in China. Mycologia 2016, 108, 993-1009. [CrossRef] [PubMed] 
13. Zilker, T.; Faulstich, H. Cyclopeptide-Containing Mushrooms: The Deadly Amanitas. In Critical Care Toxicology: Diagnosis and Management of the Critically Poisoned Patient, 2nd ed.; Brent, J., Burkhart, K., Dargan, P., Hatten, B., Megarbane, B., Palmer, R., White, J., Eds.; Springer International Publishing: Cham, Switzerland, 2017; pp. 2129-2148. [CrossRef]

14. Karlson-Stiber, C.; Persson, H. Cytotoxic fungi-An overview. Toxicon 2003, 42, 339-349. [CrossRef]

15. Enjalbert, F.; Rapior, S.; Nouguier-Soule, J.; Guillon, S.; Amouroux, N.; Cabot, C. Treatment of Amatoxin poisoning: 20-year retrospective analysis. J. Toxicol. Clin. Toxicol. 2002, 40, 715-757. [CrossRef]

16. Hallen, H.E.; Watling, R.; Adams, G.C. Taxonomy and toxicity of Conocybe lactea and related species. Mycol. Res. 2003, 107, 969-979. [CrossRef]

17. Jahn, W.; Faulstich, H.; Wieland, T. Pharmacokinetics of [3H]methyl-dehydroxymethyl-amanitin in the Isolated Perfused Rat Liver, and the Influence of Several Drugs. In Amanita Toxins and Poisonings; Faulstich, H., Kommerell, B., Wieland, T., Eds.; Verlag Gerhard Witzstrock: Baden-Baden, Köln, Germany; New York, NY, USA, 1980; pp. 79-85.

18. Bushnell, D.A.; Cramer, P.; Kornberg, R.D. Structural basis of transcription: Alpha-amanitin-RNA polymerase II cocrystal at 2.8 A resolution. Proc. Natl. Acad. Sci. USA 2002, 99, 1218-1222. [CrossRef]

19. Letschert, K.; Faulstich, H.; Keller, D.; Keppler, D. Molecular characterization and inhibition of amanitin uptake into human hepatocytes. Toxicol. Sci. 2006, 91, 140-149. [CrossRef] [PubMed]

20. Schenk-Jaeger, K.M.; Rauber-Luthy, C.; Bodmer, M.; Kupferschmidt, H.; Kullak-Ublick, G.A.; Ceschi, A. Mushroom poisoning: A study on circumstances of exposure and patterns of toxicity. Eur. J. Intern. Med. 2012, 23, e85-e91. [CrossRef] [PubMed]

21. Gawlikowski, T.; Romek, M.; Satora, L. Edible mushroom-related poisoning: A study on circumstances of mushroom collection, transport, and storage. Hum. Exp. Toxicol. 2015, 34, 718-724. [CrossRef] [PubMed]

22. Garcia, J.; Costa, V.M.; Carvalho, A.; Baptista, P.; de Pinho, P.G.; de Lourdes Bastos, M.; Carvalho, F. Amanita phalloides poisoning: Mechanisms of toxicity and treatment. Food Chem. Toxicol. 2015, 86, 41-55. [CrossRef] [PubMed]

23. Ganzert, M.; Felgenhauer, N.; Schuster, T.; Eyer, F.; Gourdin, C.; Zilker, T. Amanita poisoning—comparison of silibinin with a combination of silibinin and penicillin. Dtsch. Med. Wochenschr. 2008, 133, 2261-2267. [CrossRef] [PubMed]

24. Saller, R.; Meier, R.; Brignoli, R. The use of silymarin in the treatment of liver diseases. Drugs 2001, 61, 2035-2063. [CrossRef] [PubMed]

25. Ye, Y.; Liu, Z. Management of Amanita phalloides poisoning: A literature review and update. J. Crit. Care 2018, 46, 17-22. [CrossRef] [PubMed]

26. Jaeger, A.; Jehl, F.; Flesch, F.; Sauder, P.; Kopferschmitt, J. Kinetics of amatoxins in human poisoning: Therapeutic implications. J. Toxicol. Clin. Toxicol. 1993, 31, 63-80. [CrossRef] [PubMed]

27. Butera, R.; Locatelli, C.; Coccini, T.; Manzo, L. Diagnostic accuracy of urinary amanitin in suspected mushroom poisoning: A pilot study. J. Toxicol. Clin. Toxicol. 2004, 42, 901-912. [CrossRef] [PubMed]

28. Leite, M.; Freitas, A.; Azul, A.M.; Barbosa, J.; Costa, S.; Ramos, F. Development, optimization and application of an analytical methodology by ultra performance liquid chromatography-tandem mass spectrometry for determination of amanitins in urine and liver samples. Anal. Chim. Acta 2013, 799, 77-87. [CrossRef]

29. Abbott, N.L.; Hill, K.L.; Garrett, A.; Carter, M.D.; Hamelin, E.I.; Johnson, R.C. Detection of $\alpha-$, $\beta-$, and $\gamma$-amanitin in urine by LC-MS/MS using ${ }^{15} N_{10}$ - $\alpha$-amanitin as the internal standard. Toxicon 2018, 152, 71-77. [CrossRef]

30. Bambauer, T.P.; Wagmann, L.; Maurer, H.H.; Weber, A.A.; Meyer, M.R. Development and application of a strategy for analyzing eight biomarkers in human urine to verify toxic mushroom or ricinus communis ingestions by means of hydrophilic interaction LC coupled to HRMS/MS. Talanta 2020, 213, 120847. [CrossRef]

31. Robinson-Fuentes, V.A.; Jaime-Sanchez, J.L.; Garcia-Aguilar, L.; Gomez-Peralta, M.; Vazquez-Garciduenas, M.S.; Vazquez-Marrufo, G. Determination of $\alpha$-and $\beta$-amanitin in clinical urine samples by Capillary Zone Electrophoresis. J. Pharm. Biomed. Anal. 2008, 47, 913-917. [CrossRef]

32. Garcia, J.; Costa, V.M.; Baptista, P.; de Bastos, M.L.; Carvalho, F. Quantification of alpha-amanitin in biological samples by HPLC using simultaneous UV- diode array and electrochemical detection. J. Chromatogr. B 2015, 997, 85-95. [CrossRef] 
33. Zhang, S.; Zhao, Y.; Li, H.; Zhou, S.; Chen, D.; Zhang, Y.; Yao, Q.; Sun, C. A simple and high-throughput analysis of amatoxins and phallotoxins in human plasma, serum and urine using UPLC-MS/MS combined with PRiME HLB $\mu$ Elution platform. Toxins 2016, 8, 128. [CrossRef] [PubMed]

34. Vonderschmitt, D.J.; Gautschi, K.; Frei, W.; Andres, R.Y. Radioimmunoassay for amatoxins by use of a rapid, 125I-tracer-based system. Clin. Chem. 1986, 32, 1751-1755. [CrossRef]

35. Maurer, H.H.; Schmitt, C.J.; Weber, A.A.; Kraemer, T. Validated electrospray liquid chromatographic-mass spectrometric assay for the determination of the mushroom toxins alpha- and beta-amanitin in urine after immunoaffinity extraction. J. Chromatogr. B Biomed. Sci. Appl. 2000, 748, 125-135. [CrossRef]

36. Abuknesha, R.A.; Maragkou, A. A highly sensitive and specific enzyme immunoassay for detection of $\beta$-amanitin in biological fluids. Anal. Bioanal. Chem. 2004, 379, 853-860. [CrossRef] [PubMed]

37. Bever, C.S.; Swanson, K.D.; Hamelin, E.I.; Filigenzi, M.; Poppenga, R.H.; Kaae, J.; Cheng, L.W.; Stanker, L.H. Rapid, sensitive, and accurate point-of-care detection of lethal amatoxins in urine. Toxins 2020, 12, 123. [CrossRef] [PubMed]

38. Rieck, W.; Platt, D. High-performance liquid chromatographic method for the determination of $\alpha$-amanitin and phalloidin in human plasma using the column-switching technique and its application in suspected cases of poisoning by the green species of amanita mushroom (Amanita phalloides). J. Chromatogr. B Biomed. Sci. Appl. 1988, 425, 121-134. [CrossRef]

39. Nomura, M.; Suzuki, Y.; Kaneko, R.; Ogawa, T.; Hattori, H.; Seno, H.; Ishii, A. Simple and rapid analysis of amatoxins using UPLC-MS-MS. Forensic Toxicol. 2012, 30, 185-192. [CrossRef]

40. Tanahashi, M.; Kaneko, R.; Hirata, Y.; Hamajima, M.; Arinobu, T.; Ogawa, T.; Ishii, A. Simple analysis of $\alpha$-amanitin and $\beta$-amanitin in human plasma by liquid chromatography-mass spectrometry. Forensic Toxicol. 2010, 28, 110-114. [CrossRef]

41. Filigenzi, M.S.; Poppenga, R.H.; Tiwary, A.K.; Puschner, B. Determination of $\alpha$-amanitin in serum and liver by multistage linear ion trap mass spectrometry. J. Agric. Food Chem. 2007, 55, 2784-2790. [CrossRef]

42. Helfer, A.G.; Meyer, M.R.; Michely, J.A.; Maurer, H.H. Direct analysis of the mushroom poisons alpha- and beta-amanitin in human urine using a novel on-line turbulent flow chromatography mode coupled to liquid chromatography-high resolution-mass spectrometry/mass spectrometry. J. Chromatogr. A 2014, 1325, 92-98. [CrossRef]

43. Tomkova, J.; Ondra, P.; Valka, I. Simultaneous determination of mushroom toxins $\alpha$-amanitin, $\beta$-amanitin and muscarine in human urine by solid-phase extraction and ultra-high-performance liquid chromatography coupled with ultra-high-resolution TOF mass spectrometry. Forensic Sci. Int. 2015, 251, 209-213. [CrossRef] [PubMed]

44. Sgambelluri, R.M.; Epis, S.; Sassera, D.; Luo, H.; Angelos, E.R.; Walton, J.D. Profiling of amatoxins and phallotoxins in the genus Lepiota by liquid chromatography combined with UV absorbance and mass spectrometry. Toxins 2014, 6, 2336-2347. [CrossRef] [PubMed]

45. Köppel, C. Clinical symptomatology and management of mushroom poisoning. Toxicon 1993, 31, 1513-1540. [CrossRef]

46. Busi, C.; Flume, L.; Constantino, D.; Borroni, M.; Ambrosino, G.; Olivotto, A.; Bernardini, D. Détermination des amanitines dans le sérum de patients intoxiqués par l'amanite phallö̈de [The determination of amanitines in the serum of patients poisoned by Amanita phalloides (author's transl)]. Nouv. Presse Med. 1977, 6, 2855-2857. [PubMed]

47. Luo, H.; DuBois, B.; Sgambelluri, R.M.; Angelos, E.R.; Li, X.; Holmes, D.; Walton, J.D. Production of ${ }^{15} \mathrm{~N}$-labeled $\alpha$-amanitin in Galerina marginata. Toxicon 2015, 103, 60-64. [CrossRef]

48. Maurer, H.H.; Kraemer, T.; Ledvinka, O.; Schmitt, C.J.; Weber, A.A. Gas chromatography-mass spectrometry (GC-MS) and liquid chromatography-mass spectrometry (LC-MS) in toxicological analysis. Studies on the detection of clobenzorex and its metabolites within a systematic toxicological analysis procedure by GC-MS and by immunoassay and studies on the detection of $\alpha$ - and $\beta$-amanitin in urine by atmospheric pressure ionization electrospray LC-MS. J. Chromatogr. B Biomed. Sci. Appl. 1997, 689, 81-89. [CrossRef]

49. ICH. M10 Guideline on Bioanalytical Method Validation Step 2b. Available online: https: //www.ema.europa.eu/en/documents/scientific-guideline/draft-ich-guideline-m10-bioanalytical-methodvalidation-step-2b_en.pdf (accessed on 5 August 2020). 
50. Li, C.; Wei, F.; Muhammad, S.; Yang, G.; Wang, S.; Liu, X. A cost-effective LC-MS/MS method for identification and quantification of alpha-amanitin in rat plasma: Application to toxicokinetic study. J. Chromatogr. B 2017, 1064, 36-39. [CrossRef]

51. Jehl, F.; Gallion, C.; Birckel, P.; Jaeger, A.; Flesch, F.; Minck, R. Determination of $\alpha$-amanitin and $\beta$-amanitin in human biological fluids by high-performance liquid chromatography. Anal. Biochem. 1985, 149, 35-42. [CrossRef]

52. Helfer, A.G.; Michely, J.A.; Weber, A.A.; Meyer, M.R.; Maurer, H.H. Orbitrap technology for comprehensive metabolite-based liquid chromatographic-high resolution-tandem mass spectrometric urine drug screening exemplified for cardiovascular drugs. Anal. Chim. Acta 2015, 891, 221-233. [CrossRef]

53. Helfer, A.G.; Michely, J.A.; Weber, A.A.; Meyer, M.R.; Maurer, H.H. Liquid chromatography-high resolution-tandem mass spectrometry using Orbitrap technology for comprehensive screening to detect drugs and their metabolites in blood plasma. Anal. Chim. Acta 2017, 965, 83-95. [CrossRef]

Publisher's Note: MDPI stays neutral with regard to jurisdictional claims in published maps and institutional affiliations.

(C) 2020 by the authors. Licensee MDPI, Basel, Switzerland. This article is an open access article distributed under the terms and conditions of the Creative Commons Attribution (CC BY) license (http://creativecommons.org/licenses/by/4.0/). 